\title{
Indicações Geográficas: agregação de valor da renda de bilro de Saubara
}

\author{
Geographical Indications: aggregation of value of \\ Saubara's bobbin lace
}

\author{
Valdir Silva Conceição ${ }^{1}$ \\ Ângela Machado Rocha ${ }^{1}$ \\ ${ }^{1}$ Universidade Federal da Bahia, Salvador, BA, Brasil
}

\begin{abstract}
Resumo
O objetivo deste trabalho é analisar a possibilidade de geração de valor da renda de bilro de Saubara por meio do registro de Indicação Geográfica (IG), verificando a evolução da importância dada ao tema, e debater a estratégica da IG como um dos instrumentos geradores de valor e os seus aspectos mercadológicos, o que proporciona um diferencial competitivo para o produto no mercado nacional e internacional. A implantação de uma IG valoriza o produto e/ou serviço, o patrimônio cultural, o território, a diversidade, a identidade e a tradição da cultura local, a propriedade intelectual e a ancestralidade com o saber-fazer, padroniza o produto, garante a qualidade, capacita a mão de obra entre outros benefícios para a comunidade.A pesquisa foi empírica e de caráter qualitativo. Em relação ao método, utilizou-se a pesquisa bibliográfica, realizou-se a revisão da literatura sobre a renda de bilro no município de Saubara, a Indicação Geográfica (IG) e os benefícios advindos do seu registro para as rendeiras e para o território no qual se encontra inserido.
\end{abstract}

Palavras-chave: Renda de Bilro. Saubara. Indicação Geográfica.

\begin{abstract}
The objective is to analyze the possibility of generating value of the Saubara bobbin lace through the Geographical Indication (GI) registry, verifying the evolution of the importance given to the topic, as well as discussing the fundamental and strategic importance of the GI as one of the generating instruments of value and its market aspects, which provides a competitive differential for the product in the national and international market. The implementation of a GI values the product and/or service, cultural heritage, territory, diversity, identity and tradition of local culture, intellectual property and ancestry with know-how, standardize the product, guarantee the quality, empowering the workforce among other benefits to the community. The research will be of the empirical type and qualitative, using bibliographical research as a method, a review of the literature on bobbin lace, the municipality of Saubara and the GI and the added benefits derived from the registration of a GI for rendeiras and to the territory in which it is inserted.
\end{abstract}

Keywords: Bobbin Lace. Saubara. Geographical Indication.

Área Tecnológica: Indicação Geográfica. 


\section{Introdução}

Os produtos possuem características inatas ou moldadas pela intervenção humana e algumas delas podem estar ligadas diretamente com a sua qualidade. As características de origem (local de produção), independentemente se o processamento é natural ou com a intervenção humana (manual ou industrial), podem indicar a sua procedência, o que pode conferir um grau de qualidade ou reputação e um controle único dessas características. Isso cria um fator diferenciado para o produto e/ou serviço e para o território. Vale ressaltar que, no processo produtivo, além das técnicas e da matéria prima, há a característica do "saber-fazer" ou "knowhow" que se entrelaça com a cultura, a história e a tradição (VELLOSO, 2008).

Quando é possível identificar a procedência do produto e a garantia do seu controle, o valor desse produto tende a ser superior ao preço médio praticado no mercado, com materiais similares e que não tenham um controle dessa qualidade e das características inerentes ao produto, o que confere credibilidade, empoderamento e respeito ao seu potencial consumidor.

Existem alguns produtos que possuem notoriedade, possuem qualidade certificada e são identificados como uma IG como o Champagne, que é um tipo de vinho espumante e é proveniente da região de mesmo nome; o presunto da região de Parma, na Itália; e os charutos cubanos. No Brasil, podem ser citados os vinhos do Vale dos Vinhedos, no Rio Grande do Sul; a cachaça de Ubaíra, na Bahia, entre outros (NASCIMENTO et al., 2012).

Segundo a Organização Mundial de Propriedade Intelectual (OMPI, 2012), o registro de Indicação Geográfica (IG) é conferido a produtos ou serviços que são característicos do seu local de origem, o que lhes atribui reputação, valor intrínseco e identidade própria, além de distingui-los em relação aos seus similares disponíveis no mercado.

A IG é uma forma especial de proteção aos bens materiais e imateriais, sendo uma especialidade de Direito, no campo da Propriedade Intelectual. Ela é muito importante nesse mundo globalizado de mercados, organizado em blocos econômicos e competitivos (característica inerente do capitalismo), em que os produtos e/ou serviços requerem qualidade e confiabilidade por parte do usuário. O seu principal objetivo é a distinção do produto e/ou serviço por meio da diferenciação da qualidade inerente ou então pela fama decorrente da sua região geográfica de comercialização ou de obtenção do mesmo. Ela confere a possibilidade de agregação de valor ao produto e/ou serviço, a cooperação entre produtores, o alinhamento com a competitividade, a fidelização, a identificação e a notoriedade, além de protegê-lo de imitações e falsificações, da concorrência desleal ou do seu uso indevido, gerando ganho econômico e social para a comunidade e a identificação da sua origem de determinado local ou região (ALBINO; CARLS, 2015). A valoração do produto com IG decorre da qualidade dos produtos e dos serviços e o território como fonte que se converge e se reforça de forma mútua, o que serve de fio condutor para uma nova estratégia de desenvolvimento territorial (VELLOSO, 2008).

A Lei de Propriedade Industrial - Lei n. 9.279/96 - (BRASIL, 1996) é o instrumento de parametrização da caracterização da IG, que indica as ferramentas e os critérios necessários para a realização do pedido, os direitos do titular da IG e a proteção do consumidor e do produtor.

No município de Saubara, localizado no Recôncavo da Bahia, a renda de bilro é um artesanato que ganhou fama internacional, pois é produzida fundamentalmente por mulheres a partir do cruzamento e do entrelaçamento de linhas, ofício passado de geração em geração e 
que perpetua na história e na ancestralidade com a transmissão dos saberes e resiste aos movimentos históricos de dominação (SILVA, 2017).

A Associação das Rendeiras de Saubara conta atualmente com cerca de 110 associadas e o seu início data da década de 1980, quando o grupo começa a se organizar e a ter apoio de entidades privadas e do poder público. O trabalho da Associação baseia-se na preservação de aspectos culturais, como o uso de linha de algodão de cor branca, formato tradicional da renda, e trabalho solidário como princípio definido por todas as rendeiras.

As rendeiras já foram premiadas duas vezes com o prêmio Top 10 do Sebrae, o que valoriza ainda mais a renda de Saubara, levando o Governo do Estado da Bahia e a Universidade Federal da Bahia (UFBA) a firmarem um Termo de Cooperação Técnica, cujo objetivo é a delimitação da área geográfica pertencente a comunidade de Saubara, de forma que possa subsidiar o processo a ser instalado junto ao Instituto Nacional de Propriedade Industrial (INPI), visando ao registro da produção artesanal para a solicitação de IG (CALDAS, 2017).

No Brasil, existem 49 Indicações de Procedência (IP) concedidas e são todas nacionais, 18 Denominação de Origem (DO), sendo 10 nacionais e oito estrangeiras, 16 depositadas, sendo 10 IP e seis DOs. A Bahia possui registrados dois IPs, em fase de registro um IP e um DO. Dividido com Pernambuco, possui registrada um IP. Em fase de concessão, oito DOs e quatro IPs (INSTITUTO NACIONAL DE PROPRIEDADE INDUSTRIAL, 2018).

O presente trabalho visa a apresentar uma síntese do levantamento e potencialidade de IG para a renda de bilro de Saubara, utilizando como método a pesquisa bibliográfica, além de mostrar a importância do registro da IG da renda de bilro para a comunidade, preservação da ancestralidade, perpetuação da arte, valorização do patrimônio e proteção da propriedade intelectual de Saubara.

\section{Metodologia}

O estudo foi realizado de forma exploratória descritiva, com base em dados encontrados no sítio do INPI e em sítios da internet, livros, artigos e monografias em que havia informações relevantes para enriquecer o trabalho e a aprendizagem. A pesquisa utilizou como palavra-chave "Renda de Bilro" "Indicação Geográfica" e "Saubara". Também foi feita a prospecção de dados secundários relativos ao tema e coleta de dados referentes ao município e as suas condições geográficas que fossem relevantes para o desenvolvimento do trabalho.

\section{Referencial Teórico}

Desde os primórdios da era romana, os produtos eram rotulados e valorizados de acordo com a sua procedência e origem. Tem-se como exemplo os mármores de Carrara, na região da Toscana, assim como os vinhos de Falerne na Itália e os de Corínthio, Ícaro e Rhodes na Grécia (ALBINO; CARLS, 2015). A Bíblia cita indicações de origem como os vinhos de En-Gedi e o cedro do Libano (CERDAN et al., 2014). Segundo Almeida (2010 apud MARANHÃO, 2015, p. 26), "[...] já foram encontrados vestígios datados de 3.500 (três mil e quinhentos) anos antes de Cristo que, na cidade de Saqquarah (Egito), faziam referência aos vinhos de Letopoli e de Pelusa". 
O surgimento da IG deve-se ao fato de produtores, comerciantes e consumidores começarem a identificar que alguns produtos apresentavam determinadas qualidades que eram atribuíveis a determinadas regiões geográficas e, a partir dessa constatação, passaram a denominar os produtos com o nome geográfico, cujo sentido indicava a procedência do produto, o que, de certa forma, agregava valor e essa qualidade superior e gerava um maior incremento na demanda. Tradicionalmente, são vinculados a produto de origem agropecuária (VALENTE, 2012).

A IG consolidou-se na Europa no século XX, quando foi registrado um maior aumento na demanda pela proteção dos seus produtos, de forma a evitar imitações, requerendo um maior nível de proteção por parte da Organização Mundial de Comércio (OMC), por meio do acordo TRIPS, assinado em Marrakesh, Marrocos, em 15 de abril de 1994. Esse acordo estabeleceu novos patamares de proteção à propriedade intelectual, incluindo à proteção a IG, sendo o Brasil um dos signatários desse acordo em 1994 (DUPIM, 2012). Os consumidores começaram a perceber que os produtos tinham particularidades de acordo com a sua origem e a qualidade era diferente de outros produtos similares e pertencentes à outra região ou então a outro modo de fabricar; daí de forma gradativa começaram a denominar o produto que se destacava dos outros pela sua procedência geográfica. Os produtos que apresentaram inicialmente essas características foram os vinhos, que eram influenciados por fatores naturas como o solo, o clima, o relevo etc.

A IG destaca a particularidade de diversos produtos provenientes de diferentes regiões, valorizando-a, criando um fator que diferencia o produto e o local, apresentando características próprias e originais (CERDAN et al., 2014). A diferenciação pode estar ligada a um sabor peculiar existente apenas no local devido a uma intervenção humana ou de ocorrência natural, aspectos ambientais como o clima, o solo, o relevo, a temperatura etc. Também pode estar ligada a uma tradição local e histórica, além de outros caracteres como os socioambientais, o saber fazer (modo de produção), etc. A diferenciação é um fator preponderante para os pequenos produtores que, nessas condições, se capacitam para concorrer contra os grandes e não se tornam excluídos do sistema capitalista (VELLOSO, 2008).

Um produto ou serviço que se enquadre como IP tem o direito de exclusividade de acordo com a lei de utilizar o nome geográfico do local onde ele é gerado. No caso de uma DO, além do nome geográfico, torna-se necessário atribuir o estabelecimento do local assim como o atendimento dos requisitos de qualidade.

O Instituto Nacional de Propriedade Intelectual (INPI) é uma autarquia federal vinculada ao Ministério do Desenvolvimento, Indústria e Comércio Exterior que tem como função executar no âmbito nacional as normas que regulam a propriedade industrial, tendo entre os seus atributos a concessão de patentes, o registro de marcas, a averbação de contratos de transferência de tecnologia, além de conceder outros registros.

A Lei da Propriedade Industrial (Lei n. 9.279/96) estabelece as seguintes condições para registro das indicações geográficas de acordo com os artigos 176 a 182: 
Quadro 1 - Artigos da Lei n. 9.279/96

\begin{tabular}{|c|c|}
\hline Artigo & Descrição \\
\hline 176 & Constitui indicações geográficas a indicação de procedência ou a denominação de origem. \\
\hline 177 & $\begin{array}{l}\text { Considera-se indicação de procedência o nome geográfico de país, cidade, região ou } \\
\text { localidade de seu território, que se tenha tornado conhecido como centro de atração, } \\
\text { produção ou fabricação de determinado produto ou de prestação de determinado serviço. }\end{array}$ \\
\hline 178 & $\begin{array}{l}\text { Considera-se denominação de origem o nome geográfico de país, cidade, região ou localidade } \\
\text { de seu território, que designe produto ou serviços cujas qualidades ou característica devam } \\
\text { exclusivamente ou essencialmente ao meio geográfico, incluídos fatores naturais e humanos. }\end{array}$ \\
\hline 179 & $\begin{array}{l}\text { A proteção estender-se-á à representação gráfica ou figurativa da indicação } \\
\text { geográfica, bem como à representação geográfica de país, cidade, região ou } \\
\text { localidade de seu território cujo nome seja indicação geográfica. }\end{array}$ \\
\hline 180 & $\begin{array}{l}\text { Quando o nome geográfico, se houver tornado de uso comum, designando } \\
\text { produto ou serviço, não será considerado indicação geográfica. }\end{array}$ \\
\hline 181 & $\begin{array}{l}\text { O nome geográfico que não constitua indicação de procedência ou } \\
\text { denominação de origem poderá servir de elemento característico de marca } \\
\text { para produto ou serviço, desde que não induza falsa procedência. }\end{array}$ \\
\hline 182 & $\begin{array}{l}\text { O uso da indicação geográfica é restrito aos produtores e prestadores } \\
\text { de serviço estabelecidos no local, exigindo-se, ainda, em relação às } \\
\text { denominações de origem, o atendimento de requisitos de qualidade. }\end{array}$ \\
\hline $\begin{array}{l}\text { Parágrafo } \\
\text { único }\end{array}$ & O INPI estabelecerá as condições de registro das indicações geográficas. \\
\hline
\end{tabular}

Fonte: Adaptado de Brasil (1996)

$\mathrm{O}$ artigo $2^{\circ}$ da Instrução Normativa n. 25, de 21 de agosto de 2013, define o seguinte:

Para os fins dessa Instrução Normativa, constitui Indicação Geográfica a Indicação de Procedência e a Denominação de Origem.

$\S 1^{\circ}$ Considera-se a Indicação de Procedência o nome geográfico do país, cidade, região ou localidade de seu território, que tenha se tornado conhecido como centro de extração, produção ou fabricação de determinado produto ou de prestação de determinado serviço.

$\S 2^{\circ}$ Considera-se a Denominação de Origem o nome geográfico do país, cidade, região ou localidade de seu território, que designa produto ou serviço cujas qualidades ou características se devam exclusiva ou essencialmente ao meio geográfico, incluindo fatores naturais e humanos. (BRASIL, 2013, art. $2^{\circ}$ )

Para o pedido de registro do IG é preciso utilizar as recomendações escritas no artigo $6^{\circ}$ da Instrução Normativa n. 25, de 21 de agosto de 2013, constando do seguinte: 
Quadro 2 - Documentação necessária para solicitação de registro IG

\begin{tabular}{|c|c|}
\hline Categoria & DocumENTAÇÃo \\
\hline $\begin{array}{c}\text { Documentação } \\
\text { geral conforme } \\
\text { artigo 60 } \\
\text { (comum a } \\
\text { IP e DO) }\end{array}$ & $\begin{array}{l}\text { i) Requerimento (modelo I) do qual conste: a) o nome } \\
\text { geográfico; b) a descrição do produto ou serviço; } \\
\text { ii) instrumento hábil a comprovar a legitimidade do requerente; } \\
\text { iii) regulamento de uso do nome geográfico; } \\
\text { iv) instrumento oficial que delimita a área geográfica; } \\
\text { v) etiquetas, quando se tratar de representação gráfica ou figurativa da IG } \\
\text { ou de representação de país, cidade, região ou localidade do território, } \\
\text { bem como sua versão em arquivo eletrônico de imagem; } \\
\text { vi) procuração, se for o caso; e } \\
\text { vii) comprovante do pagamento da retribuição correspondente. }\end{array}$ \\
\hline $\begin{array}{c}\text { Documentação } \\
\text { complementar } \\
\text { para IP } \\
\text { conforme } \\
\text { artigo } 8^{\circ}\end{array}$ & $\begin{array}{l}\text { Para IP, além das condições estabelecidas no artigo } 6^{\circ} \text {, o pedido deverá conter: } \\
\text { a) documentos que comprovem ter o nome geográfico se tornado conhecido como } \\
\text { centro de extração, produção ou fabricação do produto ou de prestação de serviço; } \\
\text { b) documento que comprove a existência de uma estrutura de controle sobre os } \\
\text { produtores ou prestadores de serviços que tenham o direito ao uso exclusivo da IP, } \\
\text { bem como sobre o produto ou a prestação do serviço distinguido com a IP; } \\
\text { c) documento que comprove que os produtores ou prestadores de } \\
\text { serviços estão estabelecidos na área geográfica demarcada e exercendo } \\
\text { as atividades de produção ou prestação do serviço. }\end{array}$ \\
\hline $\begin{array}{c}\text { Documentação } \\
\text { Complementar } \\
\text { para DO } \\
\text { conforme } \\
\text { artigo } 9^{\circ}\end{array}$ & $\begin{array}{l}\text { Para DO, além das condições estabelecidas no artigo } 6^{\circ} \text {, o pedido deverá conter: } \\
\text { a) elementos que identifiquem a influência do meio geográfico na qualidade } \\
\text { ou nas características do produto ou serviço que se devam exclusivamente ou } \\
\text { essencialmente ao meio geográfico, incluindo fatores naturais e humanos; } \\
\text { b) descrição do processo ou método de obtenção do produto } \\
\text { ou serviço, que devem ser locais, leais e constantes; } \\
\text { c) documento que comprove a existência de uma estrutura de controle sobre os } \\
\text { produtores ou prestadores de serviços que tenham o direito ao uso exclusivo da } \\
\text { DO, bem como sobre o produto ou prestação do serviço distinguido com a DO; } \\
\text { d) documento que comprove que os produtores ou prestadores de } \\
\text { serviços estão estabelecidos na área geográfica demarcada e exercendo } \\
\text { as atividades de produção ou de prestação do serviço. }\end{array}$ \\
\hline
\end{tabular}

Fonte: Rezende et al. (2015)

O encaminhamento da documentação ao INPI deve ser feito pela Associação, constando toda a documentação citada no Quadro 2.

\section{Resultados e Discussão}

A IG representa um ativo intangível para quem o possui e representa um valor agregado, dá uma marca comum aos produtos da localidade, serve como parâmetro nos momentos de exportação.

Para o consumidor, o selo representa um produto de qualidade, genuíno, específico de um local e confiável. Essa condição representa um fator preponderante para que produtores e fabricantes almejem o registro do seu produto ou serviço para diferenciá-lo dos similares dos concorrentes.

Para obter êxito no registro de uma IG, há a necessidade inicial de o produtor criar uma entidade representativa para congregar os interessados em obter o selo e que esse produtor esteja disposto com um padrão de qualidade, o que ocasionará em um desenvolvimento do negócio e da região. 
Os principais objetivos da IG são: promoção comercial; garantia de autenticidade; agregação de valor ao produto; promoção do desenvolvimento regional; preservação da biodiversidade, do conhecimento tradicional e dos recursos naturais (BRASIL, 2008). Entre os benefícios trazidos pela IG, podem ser citados: benefícios baseados na proteção; benefícios baseados no desenvolvimento rural; benefícios baseados na promoção e facilidades de exportação; benefícios baseados no desenvolvimento econômico (BRASIL, 2008).

A Bahia possui 417 municípios com muita diversidade, porém, o número de IG é muito baixo em relação ao seu potencial e uma das razões pode ser o desconhecimento das vantagens advindas da concessão do selo. Outra vantagem é a capacidade de exportação do produto ou serviço para outros países, além da geração expressiva de valor econômico e o desenvolvimento local, com a possibilidade de incrementar o turismo na região.

\subsection{Renda de Bilro}

O artesanato é uma atividade laboral que visa a um ganho financeiro. É uma forma de mostrar a riqueza, a diversidade, a identidade e a tradição da cultura do local, que sofreram influência dos índios, dos escravos e dos imigrantes de diversas nacionalidades que se fixaram no país, sendo essa condição uma marca da sua ocupação econômica e social (LEAHY, 2012).

A renda de bilro é uma das mais antigas manifestações da arte brasileira e sua confecção teve início durante a colonização, sempre foi realizada por mulheres que tinham algum tipo de ligação com o mar, seja na condição de esposa de pescadores, seja na condição de marisqueira, pois o ofício de rendeira ocorre mais especificamente na região litorânea ou ribeirinha e nas adjacências. Ela é quase sempre feita por mulheres de condição humilde que utilizam das suas habilidades, criatividades e destrezas na confecção da renda. Os trabalhos manuais faziam parte da formação feminina, por serem necessários para as mulheres desenvolverem a sua relação artístico-doméstica (BRUSSI, 2009).

A sua introdução no país ocorreu no período da colonização, quando as mulheres portuguesas deixavam a sua terra natal em busca de uma vida melhor no novo continente, trazendo consigo uma herança cultural acumulada de séculos de trabalho, para manter viva a sua cultura de origem. A sua procedência era da região litorânea de Portugal onde tradicionalmente os homens viviam da pesca e as mulheres utilizavam essa arte como um passatempo na espera dos seus maridos que ficavam um bom tempo no mar.

Os materiais utilizados para a confecção da renda variam de cidade e de país conforme a cultura local. Dependendo da região, as variantes dos modelos das almofadas são as seguintes: a almofada de cavalete, a cilíndrica, a conservatória e a de rebolo ou redonda. Em Saubara, as almofadas utilizadas são cilíndricas e possuem dimensões variando de $40 \mathrm{~cm}$ a $70 \mathrm{~cm}$ de comprimento, podendo chegar a um metro como já foi no passado. Essa variação no comprimento determina o tamanho da renda a ser fabricada e a quantidade de pessoas que vão trabalhar de forma simultânea (LEAHY, 2012).

A renda de Saubara é uma renda que você não encontra em lugar nenhum. Tem outros lugares, nos outros estados aqui do Brasil tem renda de bilro, mas é totalmente diferente da nossa [...] Eu sinto que a renda de Saubara é diferenciada, tanto no modo de fazer como no trançado, e também na matéria prima, nós temos tudo diferenciado. (SILVA, 2017, p. 155) 
Antigamente, a renda de bilro era confeccionada nas residências das rendeiras e, por essa razão, havia dificuldades de comercialização. Os compradores tinham que procurar o produto indo de casa em casa, o que também se constituía uma dificuldade e uma das formas encontradas para facilitar a comercialização e divulgação do produto foi por meio da criação da Associação de Artesãos de Saubara, que é denominada pela população local como "Casa das Rendeiras". Ela foi criada em 31 de agosto de 1999, sendo inicialmente composta de 45 rendeiras, e seu objetivo era comercializar produtos relacionados à renda de bilro e ao trançado de palhas dos associados (AMORIM, 2010).

A obtenção de recursos é proveniente das vendas realizadas em feiras de Salvador, na Legião Brasileira de Assistência (LBA), no Serviço Social da Indústria (SESI), no Instituto Mauá e no Serviço Brasileiro de Apoio às Micro e Pequenas Empresas (SEBRAE). Entre os seus objetivos encontra-se fazer a ligação entre os produtores e a sociedade consumidora, com os entes públicos, como um estimulador e divulgador da atividade, além de servir como um gerador do resgate cultural dessa atividade e capacitador da mão de obra. A associação já foi premiada duas vezes no Top 100 de Artesanato, que é considerado uma das grandes honrarias desse segmento econômico, sendo a primeira vez em 2004 e a segunda vez em 2016 (AMORIM, 2010). Os agraciados recebem um selo de qualidade para os seus produtos, tornando-o competitivo, além de servir como difusor do ofício de rendeira, engrandecendo a mulher rendeira e difundindo a cultura.

\subsection{Saubara}

A sua história vem de um tempo anterior à colonização portuguesa, pois era uma região habitada pelos índios Tupis e o seu nome deriva da formiga "saúva" que era abundante no local e teve como nome "Sauvara" que significa terra dos comedores de formiga. Quando a região foi colonizada pelos espanhóis teve a variação do nome para Saubara (BARROS, 2017). Segundo o Instituto do Patrimônio Artístico e Cultural (IPAC), o povoado surgiu por volta de 1550, sendo um dos primeiros aglomerados de Santo Amaro. A freguesia de São Domingos de Saubara foi constituída a partir da construção da Igreja dedicada a São Domingos de Gusmão, construída pelos moradores da Ponta de Saubara - região à beira-mar e fundada pelo fidalgo português Braz Fragoso em 1685 - para que os protegessem em alto mar, servindo também de quartel general nas lutas pela Independência na Bahia, já que da parte alta seria possível observar a chegada dos invasores portugueses.

Saubara é uma das mais antigas aglomerações urbanas do Recôncavo Baiano, localizada na Baía de Todos os Santos, formada no século XVI com a colonização portuguesa, no litoral, com clima úmido e paisagem diversificada contendo praias, rios, mangue, falésia, cascata. Inicialmente, era um distrito subordinado a Santo Amaro pela Lei Provincial n. 1.619, de 4 de julho de 1876, foi elevado a vila em 1955 e foi emancipada de Santo Amaro em 1989 pela Lei n. 5.009 (JESUS; PROST, 2011).

Com área total de $163,50 \mathrm{~km}^{2}$, altitude de 10 metros e coordenadas geográficas sexagesimais a 1244'16" de latitude Sul e 38 46'09" de longitude Oeste, faz limite com os municípios de Salvador, São Francisco do Conde e Madre de Deus (E); Santo Amaro (N); Cachoeira (W); e Maragogipe e Salina das Margaridas (S). O seu clima varia de úmido a subúmido, com temperatura média anual em torno de $23,4^{\circ} \mathrm{C}$ e pluviosidade média anual entre $1.139 \mathrm{~mm}$. Faz 
parte da Mesorregião Metropolitana de Salvador e da Microrregião de Santo Antônio de Jesus (INSTITUTO BRASILEIRO DE GEOGRAFIA E ESTATÍSTICA, 2017).

A cidade de Saubara, a $100 \mathrm{~km}$ de Salvador por terra e $20 \mathrm{~km}$ marítimo, tem ganhado destaque como produtora de artesanato do tipo renda de bilro, que é a principal atividade artesanal da comunidade. O local se constitui como um dos polos mais tradicionais de produção de renda, abastecendo o mercado nacional, exportando para países da Europa como Itália e Portugal e tornando-se conhecida mundialmente devido a essa arte.

\subsection{Potencialidades de IG}

A IG pode proporcionar ao estado um aumento no valor cultural agregado e o atendimento de requisitos de qualidade, diferenciando o produto de outros similares, além de ser um fator estratégico para desenvolvimento da região, geração de riqueza, agregação de valor. Proporciona também originalidade ao produto local, proporcionando a expansão na participação dos mercados locais, nacionais e internacionais, fortalecendo a competitividade do produto ou serviço. Também protege e valoriza a cultura local, preserva as tradições, gera emprego direto e indireto, reduz a possibilidade de êxodo e gera a criação de produtos e/ou serviços com qualidade para atender as necessidades dos clientes e propiciar o desenvolvimento por meio da propriedade intelectual (VELLOSO, 2008).

As associações e cooperativas possuem um papel fundamental no desenvolvimento do potencial dos seus afiliados, com o gerenciamento dos produtos fabricados, treinamento $e$ capacitação, divulgação e qualificação, preservação das diferentes tradições e valorização da cultura local, organização dos atores e o seu fortalecimento.

\section{Considerações Finais}

As Indicações Geográficas são instrumentos que servem para rastrear o produto, determinar o seu local de origem, padronizar o produto, garantir a qualidade do produto, distinguir os produtos e/ou serviços, evitar o uso indevido e inibir falsificações, proteger o consumidor, evitar concorrência desleal, potencializar o produto, valorizar o produto, e capacitar a organização e a identificação dos produtores. Visa à proteção do patrimônio intangível e preservação da biodiversidade local, fomentando a possibilidade de geração de novos nichos de mercados $e$ ampliação do mercado interno e local, gerando emprego e qualificando a mão de obra.

A renda de bilro de Saubara tem potencial para ser uma Indicação Geográfica, sendo que os benefícios decorrentes desse registro serão de fundamental importância para o desenvolvimento da região, além de propiciar o reconhecimento da cultura local, da valorização do patrimônio cultural, da ancestralidade e da propriedade intelectual.

\section{Referências}

ALBINO, J.; CARLS, S. Indicações Geográficas de serviços: polêmicas do porto digital. Cad.

Prospec., Salvador, v. 8, n. 3, p. 587-594, jul./set. 2015. Disponível em: <https://portalseer.ufba.br/ index.php/nit/article/view/11627/pdf_4 >. Acesso em: 27 jun. 2018. 
AMORIM, M. C. Arte Brasil: Maria do Carmo Amorim. 2010 . Disponível em: <https://www. youtube.com/watch?v=VZim0fH5Ioo $>$. Acesso em: 10 mar. 2018.

BARROS, J. S. Ponto de Cultura: Saubara em Movimento. Catálogo. Bahia, 2017. 78 p. Disponível em: <http://marujadadesaubara.org.br/wp-content/uploads/2013/07/Catalogo_PontodeCUltura_ SaubaraemMOvimento.pdf > . Acesso em: 10 fev. 2018.

BRASIL. Instrução Normativa n. 25, 21 de agosto de 2013. Estabelece as condições para o registro das indicações geográficas. Disponível em: <http://www.inpi.gov.br/legislacao-1/in_25_21_ de_agosto_de_2013.pdf >. Acesso em: 27 jun. 2018.

Lei n. 9.279, 14 de maio de 1996. Regula direitos e obrigações relativos à propriedade industrial. Disponível em: <http://www.planalto.gov.br/ccivil_03/leis/L9279.htm>. Acesso em: 27 jun. 2018.

Ministério da Agricultura, Pecuária e Abastecimento. Guia para a solicitação de registro de indicação geográfica para produtos agropecuários. 2008. Disponível em: <http://www. agricultura.gov.br/assuntos/sustentabilidade/indicacao-geografica/arquivos-publicacoes-ig/guiapara-solicitacao-de-registro-de-indicacao-geografica-para-produtos-agropecuarios-2007.pdf/view>. Acesso em: 29 jun. 2018.

BRUSSI, J.; D. E. Da "renda roubada" à renda exportada: a produção e a comercialização da renda de bilros em dois contextos cearenses. 2009. 145 f. Dissertação (Mestrado em Antropologia Social) - Universidade Brasília, Brasília, 2009. Disponível em: <http://repositorio.unb.br/ bitstream/10482/18559/1/2009_JuliaDiasEscobarBrussi.pdf > . Acesso em: 18 jun. 2018.

CALDAS, F. Artesãos de Maragogipinho e Saubara vão buscar selo de qualidade para seus produtos com apoio da UFBA e governo estadual. [2017]. Disponível em: <http:/www. edgardigital.ufba.br/?p=2061>. Acesso em: 20 jun. 2018

CERDAN, C. M. T. et al. Indicação geográfica de produtos agropecuários: importância histórica e atual. In: BRASIL. Ministério da Agricultura, Pecuária e Abastecimento. Curso de propriedade intelectual \& inovação no agronegócio: Módulo II, indicação geográfica/Ministério da Agricultura, Pecuária e Abastecimento; organização Luiz Otávio Pimentel. 4. ed. Florianópolis: MAPA, Florianópolis: Funjab, 2014. Disponível em: <https:/www.academia.edu/11745747/ Indica\%C3\%A7\%C3\%A3o_Geogr\%C3\%A1fica_de_produtos_agropecu\%C3\%A1rios_ import\%C3\%A2ncia_hist\%C3\%B3rica_e_atual>. Acesso em: 29 jun. 2018.

DUPIM, L. C. O. Indicações Geográficas. 2012. Disponível em: <http://www.aidv.org/_media/aidv2012-dupim.pdf>. Acesso em: 10 jun. 2018.

INSTITUTO NACIONAL DE PROPRIEDADE INDUSTRIAL (INPI). [2018]. Disponível em: < https:// cidades.ibge.gov.br/brasil/ba/saubara > . Acesso em: 2 jun. 2018.

JESUS, R. S.; PROST, C. Importância da atividade artesanal de mariscagem para as populações nos municípios de Madre de Deus e Saubara, Bahia. GEOSUP - Espaço e Tempo, São Paulo, n. 30, p. 123-137, 2011. Disponível em: <https://www.revistas.usp.br/geousp/article/viewFile/74236/77879>. Acesso em: 29 jun. 2018.

LEAHY, R. C. Flor da Maré: a (re)configuração da renda de bilros por Márcia Ganem. 2012. 151 f. Dissertação (Mestrado em Cultura e Sociedade). Universidade Federal da Bahia - UFBA. Salvador, 2012. Disponível em: <http://www.poscultura.ufba.br/sites/poscultura.ufba.br/files/ Disserta\%C3\%A7\%C3\%A3o_2012\%20Renata\%20Leahy.pdf>. Acesso em: 16 jun. 2018. 
MARANHÃO, C. J. de A. Indicação Geográfica: Possibilidades do queijo colonial produzido a partir do leite cru na região de Chapecó/SC. 2015. 113 f. Dissertação (Mestrado Administração) Universidade do Oeste de Santa Catarina, Chapecó, 2015. Disponível em: <http://www.unoesc.edu. br/images/uploads/mestrado/Charlson_Maranhao.pdf >. Acesso em: 29 jun. 2018.

NASCIMENTO, J. S. et al. Indicações Geográficas: agregação de valor aos produtos brasileiros e maranhenses. Revista GEINTEC, São Cristóvão, v. 2, n. 4, p. 353-364, 2012. Disponível em: <http://www.revistageintec.net/index.php/revista/article/view/53/128>. Acesso em: 18 mar. 2018.

ORGANIZAÇÃO MUNDIAL DE PROPRIEDADE INTELECTUAL (OMPI). DL 101P BR Geographical Indications-IG-4Va. [2012]. Disponível em: <http://nit.uncisal.edu.br/wp-content/ uploads/2012/08/Indica\%C3\%A7\%C3\%B5es-Geogr\%C3\%A1ficas-IG.pdf. > . Acesso em: 18 mar. 2018.

REZENDE, A. A. et al. Considerações sobre as potenciais indicações geográficas do Sudoeste da Bahia. Revista de Política Agrícola. Brasília, DF, ano XXIV, n. 4, p. 18-31, 2015. Disponível em: $<$ http://www.agricultura.gov.br/assuntos/politica-agricola/todas-publicacoes-de-politica-agricola/ revista-de-politica-agricola/revista-de-politica-agricola-n4-2015.pdf/view > . Acesso em: 25 jun. 2018.

SILVA, D. B. P. Educação, resistências e tradição oral: a transmissão de saberes pela oralidade de matriz africana nas culturas populares, povos e comunidades tradicionais. 2017. 217 f. Dissertação (Mestrado em Educação) - Universidade de Brasília, UNB, Brasília, 2017. Disponível em: < http:// repositorio.unb.br/bitstream/10482/24411/1/2017_DanielaBarrosPonteseSilva.pdf > . Acesso em: 27 jun. 2018.

\section{VALENTE, A. M. Estudo da potencialidade de registro de indicação geográfica a produção} de cacau no município de Medicilândia/PA. 2012. 120 f. Dissertação (Mestrado em Gestão dos Recursos Naturais e Desenvolvimento Local na Amazônia) - Universidade Federal do Pará, Belém, 2012. Disponível em: <http://ppgedam.propesp.ufpa.br/ARQUIVOS/dissertacoes/2012_Dissertacao_ Andrea.de.Melo.Valente.pdf>. Acesso em: 29 jun. 2018.

VELLOSO, C. Q. Indicação geográfica e desenvolvimento territorial sustentável: a atuação dos atores sociais nas dinâmicas de desenvolvimento territorial a partir da ligação do produto ao território (um estudo de caso em Urussanga, SC). 2008. 168 f. Dissertação (Mestrado em Agroecossistemas) - Centro de Ciências Agrárias, Universidade Federal de Santa Catarina, UFSC, Florianópolis, 2008. Disponível em: < https://repositorio.ufsc.br/bitstream/ handle/123456789/91692/249759.pdf?sequence =1\&isAllowed =y>. Acesso em: 30 jun. 2018.

\section{Sobre os autores}

\section{Valdir Silva da Conceição}

E-mail: valdirconceicao@gmail.com

Pós-Graduado (Lato Sensu) em nível de especialização MBA em Gestão de Pessoas pela Realiza/Escola de Engenharia Eletro-Mecânica da Bahia (2007). Graduado em Administração pela Universidade Federal da Bahia (2018).

Endereço profissional: Escola de Administração da UFBA. Avenida Reitor Miguel Calmon, s/n, Vale do Canela, Salvador, BA. CEP: 40110-903. 


\section{Angela Machado Rocha}

E-mail:anmach@gmail.com

Doutorado em Energia e Ambiente pela Universidade Federal da Bahia (2013). Pós-Graduada (Lato Sensu) em nível de Especialização MBA em Marketing pela Fundação Getúlio Vargas (2003). Pós-Graduada (Lato Sensu)

em nível de Especialização em Engenharia de Processamento Petroquímico pela Universidade Federal da Bahia (1989).

Endereço profissional: Universidade Federal da Bahia, ICS-Instituto de Ciências da Saúde. Avenida Reitor Miguel Calmon, s/n, Canela, Salvador, BA. CEP-40210630. 